\title{
Ofício de la Virgen através da Codicologia: uma perspectiva arqueológica
}

Sirlene Corrêa Cristófano FLUP - Universidade do Porto Sirlene.cristofano@gmail.com

\begin{abstract}
The objective of this paper is to present in a succinct form Codicology as subdivision of Paleospelling, as well as to study the codex Oficio de la Virgen and to describe this support of writing from the XVI century. The study was realized on the facsimile reproduction of codex Vat. lat. 3781 of the Apostolic Vatican Library.

KEYWORDS: codicology; paleospelling; medieval Literature; codex.
\end{abstract}

\section{Introdução}

Para realizarmos o estudo de história e Literatura são necessários conhecimentos de várias ciências auxiliares. Muitos historiadores analisam e estudam documentos antigos, fazendo, assim, uma análise comparativa com outras informações já existentes, e conseguindo, com isso, desenvolver o seu trabalho e pesquisa.

Os pesquisadores historiadores estudam cuidadosamente os documentos, com base numa análise capitalista, filológica, paleográfica, diplomática, codicológica etc. Estudam questões que, para a História, estão em segundo plano, mesmo sendo reconhecido que são importantíssimos ganhos de conhecimentos históricos.

Essas ciências podem ser divididas, conforme o objectivo de estudo em questão, classificando-se em grupos denominados: a Numismática, a Esfragística e a Heráldica, que respectivamente estudam os objectos, moedas, selos e brasões; a Teologia, a Sociologia e a Etnologia, que estudam os calendários, entre outros; e a Paleografia, a Papirologia, ${ }^{1}$ a Epigrafia e a Codicologia, que estudam as fontes escritas.

O estudo ou técnica do códice, que em outras épocas pertenceu à Paleografia e à Diplomática, está hoje independente destas, com a denominação de Codicologia. ${ }^{2}$

Este trabalho tem como objectivo apresentar de forma sucinta a Codicologia como uma subdivisão da Paleografia, bem como fazer também um estudo do códice Oficio de la Virgen, e descrever este suporte da escrita do século XVI. O estudo foi feito

\footnotetext{
${ }^{1}$ A Paleografia foi consagrada por Jean Mabillon, entre os anos de 1642-1670. A principal função deste estudo era jurídica, pois servia para provar a autenticidade de documentos e provava o direito de uma pessoa sobre determinado património. Ocupava-se da decifração e ordenação de escritos antigos.

${ }^{2}$ Em alemão: Handschriftenkunde.
} 
sobre a reprodução facsimilada do códice Vat. lat. 3781 da Biblioteca Apostólica Vaticana. $^{3}$

A Codicologia é o estudo técnico, uma arte de observação de um códice, em pergaminho ou papel, que noutros tempos pertenceu ao campo da Paleografia e da Diplomática. $^{4}$

Segundo Segismundo Spina, o codicólogo necessita conhecer o quadro teórico da Codicologia para, assim, atender aos objectivos de análise e de estudo do manuscrito, em ordem a permitir a comunicação do texto e a sua praticabilidade de leitura, concentrando a atenção em eleger instrumentos de restauração do códice:

A Codicologia é atinente exclusivamente ao conhecimento do material empregado na produção do manuscrito e das condições materiais em que esse trabalho se verificou (...). ${ }^{5}$

Sendo assim, a Codicologia têm sob seu âmbito toda a produção manuscrita medieval, fixando no campo do conhecimento a localização dos códices no tempo e espaço, determinando os distintivos regionais da Scriptoria, a individualidade do copista, do decorador.

A Codicologia, vista como um domínio do saber, também estuda a qualidade e confecção do pergaminho, a procedência do papel, a combinação das tintas utilizadas na decoração, as particularidades da encadernação, maneiras de numeração, entrelinhamentos, margens colunas, reclames, tipos e dimensões das letras, os temas iconográficos e também a própria literatura. Alguns autores defendem que a Codicologia não pode ficar apenas pelo material, mas também deve analisar o tipo de texto, o conteúdo e para isso recorre-se à Paleografia.

O trabalho do codicólogo é avaliar todas as descrições realizadas mediante às observações do codex, utilizando os seguintes métodos: descrever os códigos e suas partes, comparar as diferentes maneiras da sua confecção e experimentar as diferentes técnicas utilizadas para tal.

\footnotetext{
${ }^{3}$ Oficio de la Virgen. Introducción de Eperhard Konig. Madrid: Ediciones Encuentro, 1985 (col. Ediciones facsimiles de la Biblioteca Apostolica Vaticana).

${ }^{4}$ A palavra Códice deriva do latim codex, de papel ou pergaminho: antepassado do livro impresso, confeccionado com tronco de árvore; da madeira com que se faziam tabuinhas, que cobertas de cera, podiam receber a escrita; amarradas pela margem, à moda dos livros actuais, formavam os códices; mais tarde os livros passaram a ser feitos, mas a designação de codex permaneceu.

${ }^{5}$ Spina, S. Introdução à edótica. Crítica textual. São Paulo: Ars Poética/ EDUSP, 1994, p. 22.
} 


\section{nuntius antiquus}

\section{Descrevendo e observando o codex}

\section{Manuscrito: Oficio de la Virgen}

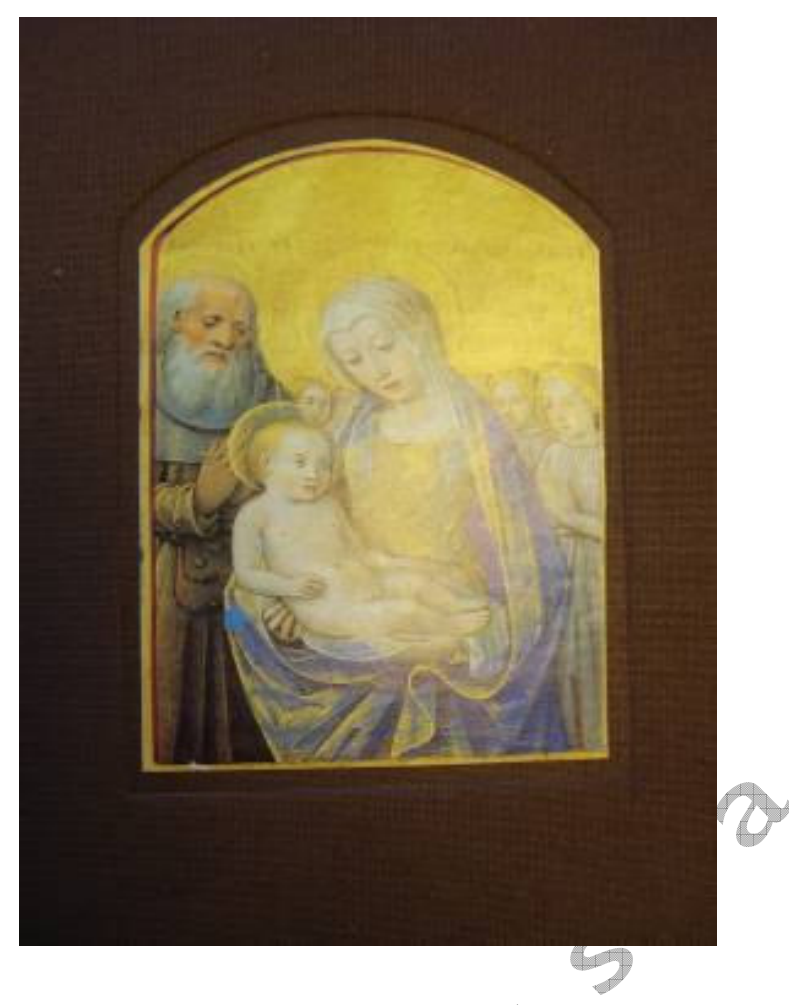

Cidade: Vaticano

Biblioteca: Biblioteca Apostólica Vaticana

Fundo: Vat. lat.

Cota: 3781

Data de catalogação: 05/ 05/ 08

N.B.: foi estudada a reprodução facsimilada Oficio de la Virgen. Introducción de Eperhard Konig. Madrid: Ediciones Encuentro, 1985 (col. Ediciones facsimiles de la Biblioteca Apostólica Vaticana).

\section{Resumo}



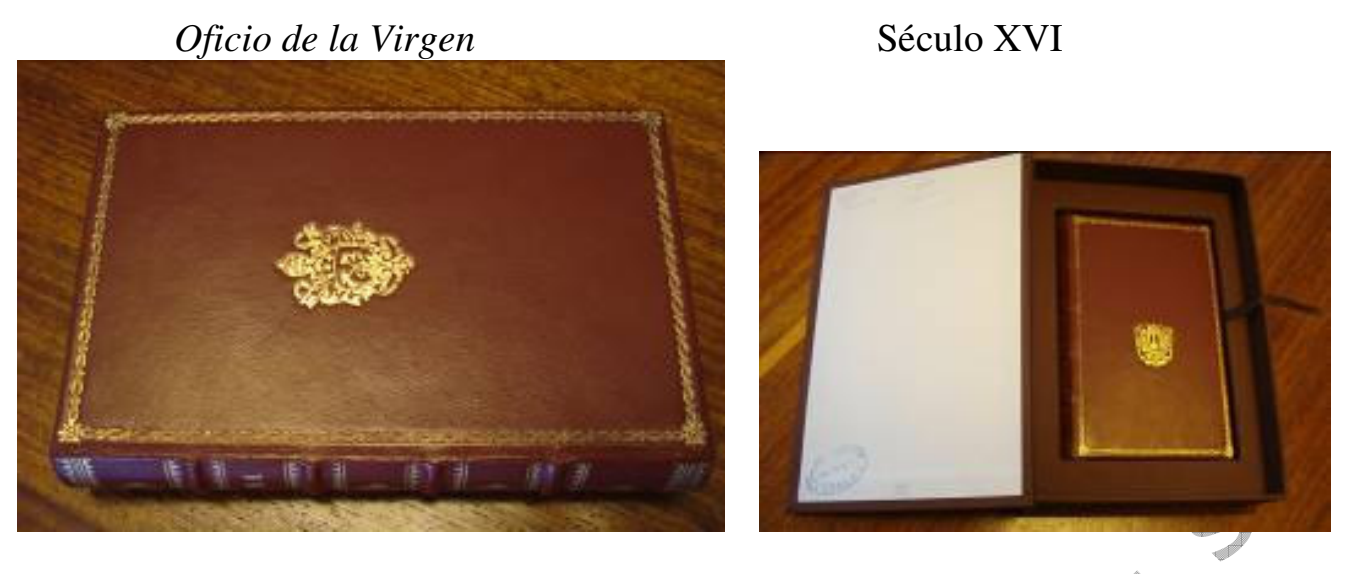

\section{Descrição do material}

\subsubsection{Número de fólios:}

O Codex contém 118 fólios de pergaminho de média qualidade e uma folha de papel acrescentada no início.

\subsubsection{Estado do manuscrito:}

O manuscrito apresenta-se conservado, com excepto a primeira folha do calendário do fólio 20. Existem poucos sinais de utilização, porém o fólio 43 apresenta a falta de um pedaço na parte inferior e os fólios $67 \mathrm{v}$ e $88 \mathrm{v}$ foram parcialmente retocados.

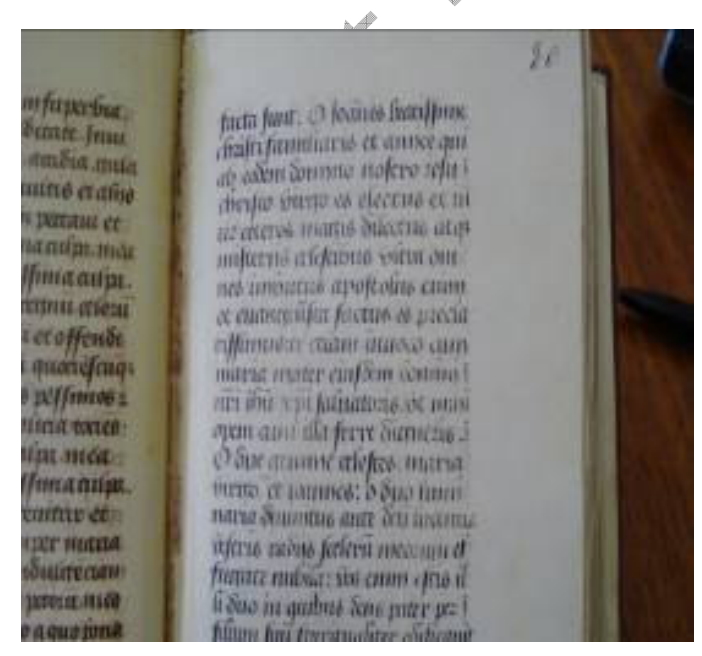

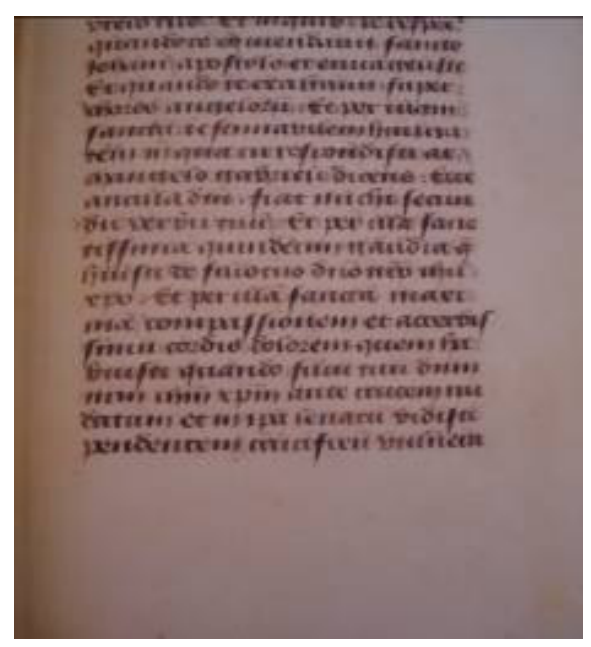

\subsection{Matéria escritória}


É um códex unitário de pergaminho, de pele de animal, sem que seja possível hoje determinar de que animal se trata com certeza. O início do manuscrito mostra-nos uma determinada mudança em relação à tonalidade do pergaminho, devido à maior quantidade de manuseio nos primeiros fólios.

\subsubsection{Cadernos:}

O códex foi organizado em 15 cadernos.
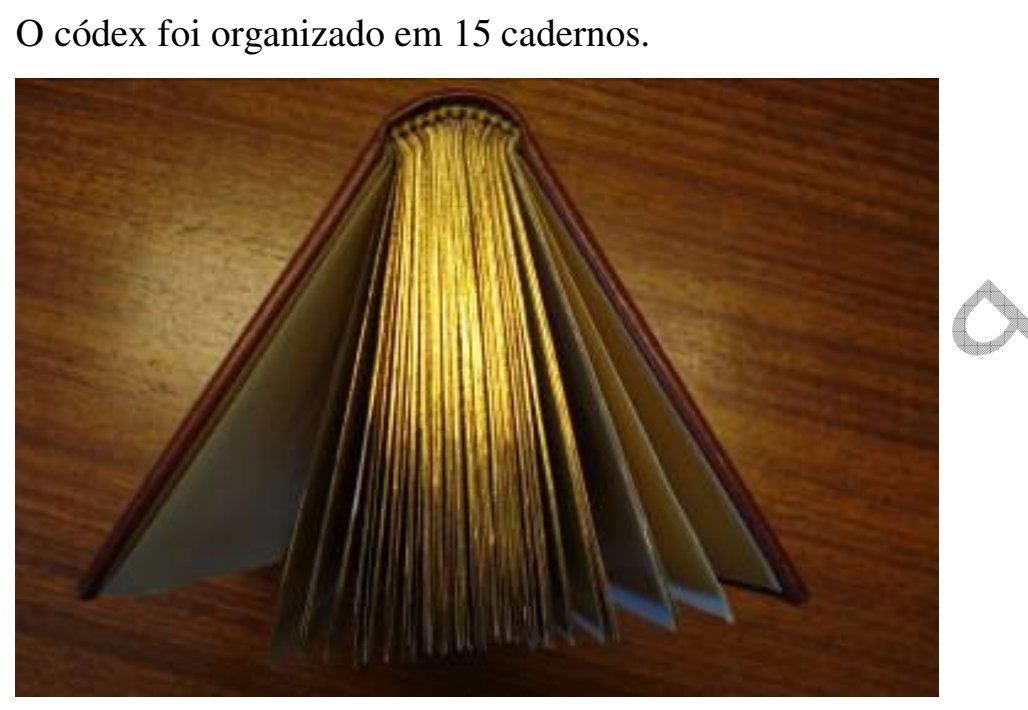

2.2.2 Descrição analítica:

a) Caderno: 1

ff. $1-5$

Tipolog. térnio

Observaçẫo:

O primeiro fólio, em branco é sem numeração é mais manchado que os restantes e não podemos determinar claramente a diferença entre a página do pelo e da carne. Podemos notar que o fólio 5, apresenta-se mais claro que o seu verso. Provavelmente substituindo um fólio que existiu antes: 


\section{nuntius antiquus}
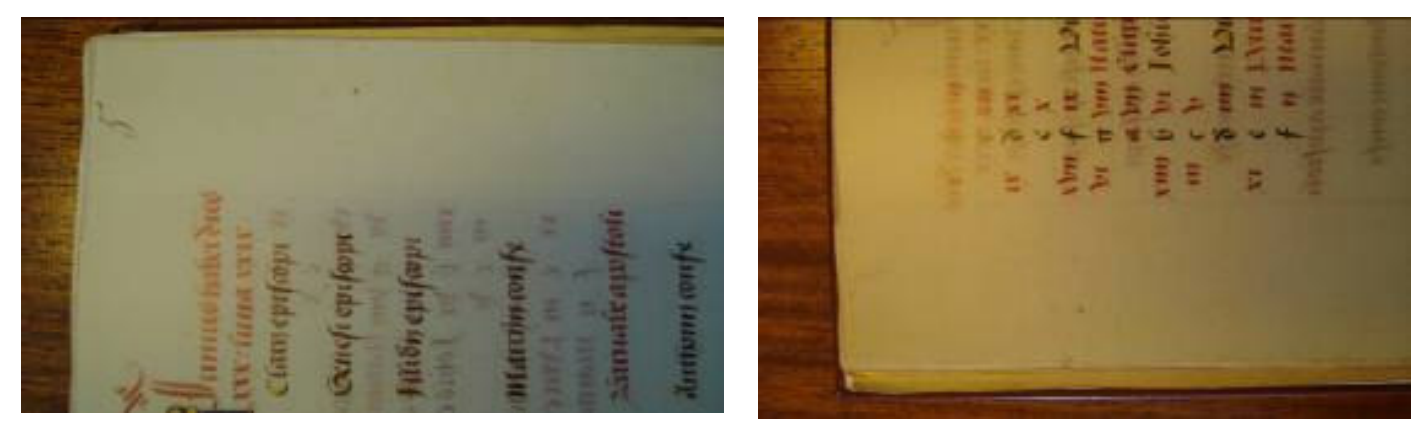

Sendo assim, o início do livro deveria começar com um caderno de seis fólios, com uma escritura regular, que alternava também as páginas da carne e as do pelo.

\section{b) Caderno: 2}

ff. $6-11$

Tipolog. térnio

Observação:

O segundo caderno encontra-se com sua conservação intacta.

c) Caderno: 3

ff. $12-16$

Tipolog. quaterno

Observação:

O terceiro caderno constituído por oito fólios apresenta uma foliação peculiar.

d) Caderno: 4

ff. $17-20$

Tipolog. bínio

Observações:

O texto continua sem interrupção no quarto caderno, que só é constituído de quatro fólios, fols. 17-20, os quais parecem uniformes e também as páginas do pergaminhos alternam-se com regularidade. Porém, a última folha, fol. 20, apresenta-se um pouco mais clara: 


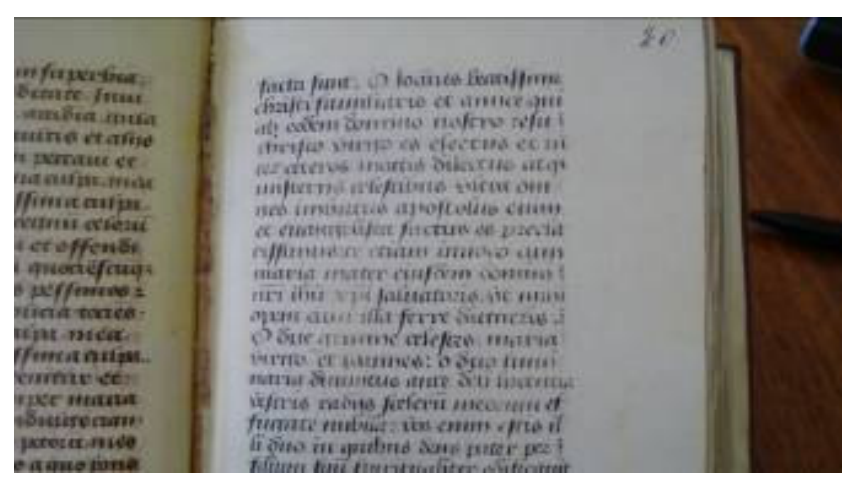

e) Caderno: 5

ff. $21-22$

Tipolog. bifólio

Observação:

Com as mesmas características do fólio 20 encontram-se os dois fólios seguintes, fols. 21-22, também mais claro, porém no fólio 21 existe o texto e o fólio 22 encontra-se completamente em branco.

f) Caderno: 6

ff. $23-30$

Tipolog. quaterno

Observação:

Assim como este, os próximos cadernos, 6 - 11, fóls. 23 - 69, mostram-nos que seguem cadernos com quatro bifólios.

g) Caderno: 7

ff. $31-37$

Tipolog. quaterno

h) Caderno: 8

ff. $38-45$

Tipolog. quaterno

Observação:

O fólio 43 encontra-se danificado na parte inferior. Possivelmente foi roído por um rato: 


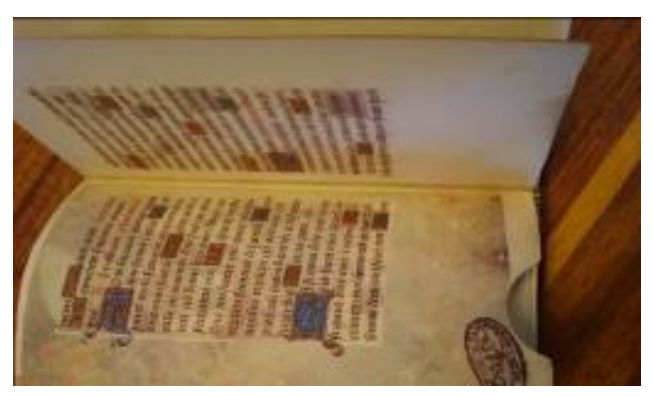

i) Caderno: 9

ff. 46 - 53

Tipolog. quaterno

j) Caderno: 10

ff. 54 - 61

Tipolog. quaterno

k) Caderno: 11

ff. $62-69$

Tipolog. quaterno

l) Caderno: 12

ff. $70-73$

Tipolog. bínio

Observação:

Os fólios 70 - 73, com três fólios em branco no final, a partir do fol. 72v.

m) Caderno: 13

ff. $74-81$

Tipolog. quaterno

n) Caderno: 14

ff. $82-89$

Tipolog. quaterno

o) Caderno: 15 


\title{
nuntius antiquus
}

\author{
ff. $89-113$
}

\section{Observação:}

O verso do fólio 113 está parcialmente em branco o que representa o final do texto, indicando que o Códice se mantém conservado quase intacto. Porém com o tempo desapareceram duas folhas: a primeira substituída por um pergaminho em branco.

\subsubsection{Numeração:}

Os fólios do manuscrito estão numerados com cifras arábicas em tinta marrom escura na margem superior direita. A numeração provavelmente foi realizada quando se fez a encadernação no final do século XVIII. O manuscrito foi foliotado, 1-113, a partir do começo do texto. Há um erro de numeração entre o f. 32 e o 34. No que se precede ao 33 , posteriormente contabilizado a lápis como $33^{\mathrm{A}} \mathrm{e}$ o fólio seguinte foliotado como $33,{ }^{\mathrm{B}}$ conforme veremos a seguir:
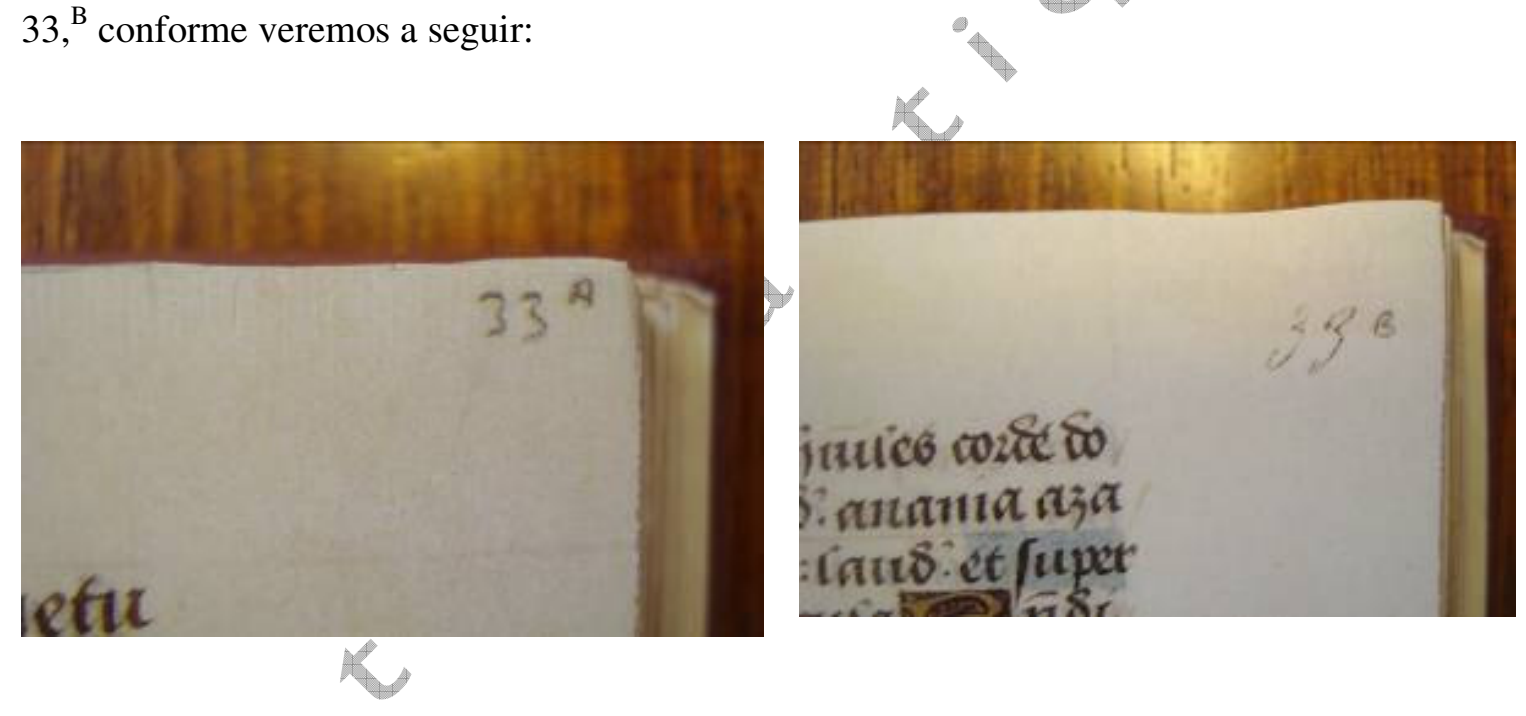

\subsubsection{Reclames:}

Não identificamos reclames no códice.

\subsubsection{Assinaturas:}

Não se encontra no último fólio de cada caderno qualquer assinatura.

\subsubsection{Regra de Gregory:}

Não há como fazer a identificação devido ao nosso material de pesquisa ser um fac-símile e não um códice original.

\subsection{Empaginação}


2.3.1 Fólio medido:

$39 \mathrm{r}$

Altura: 15,5

Largura: 9,5

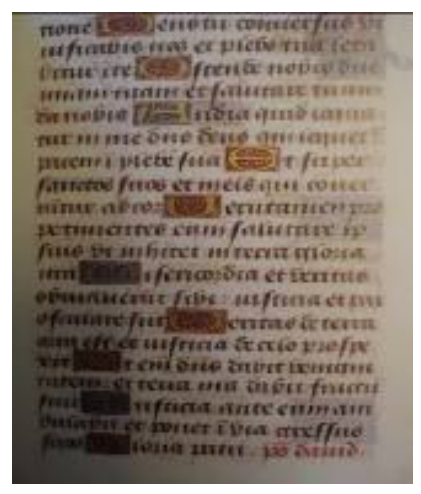

\subsubsection{Coluna:}

Não há colunas, o códice é constituído por longas linhas.

\subsubsection{Linhas:}

As linhas e colunas foram traçadas com bifólios abertos. Foi utilizado algum material para marcar as linhas e colunas.

\subsubsection{Linhas escritas:}

O copista utilizou 20 linhas escritas em tinta marrom. Contém um total de 21 linhas.

2.3.5 Largura:

$$
\text { 6,0 Centímetros. }
$$

2.3.6. Altura:

\section{9,5 Centímetros.}

2.3.7. UR:

9,5 dividido por 21: 0,4 unidade de regramento

\subsection{Picotamento}

\subsubsection{Localização:}




\section{nuntius antiquus}

É possível verificar em alguns fólios a marca dos furos realizados para marcar as colunas e linhas e que a realização desses furos foi de caderno ao caderno. Encontramos dificuldades nesta observação pelo fato do nosso material de pesquisa ser apenas um fac-símile e, sendo assim, contendo marcas pouco visíveis.

- Fólios 4v, 5r e 5v:
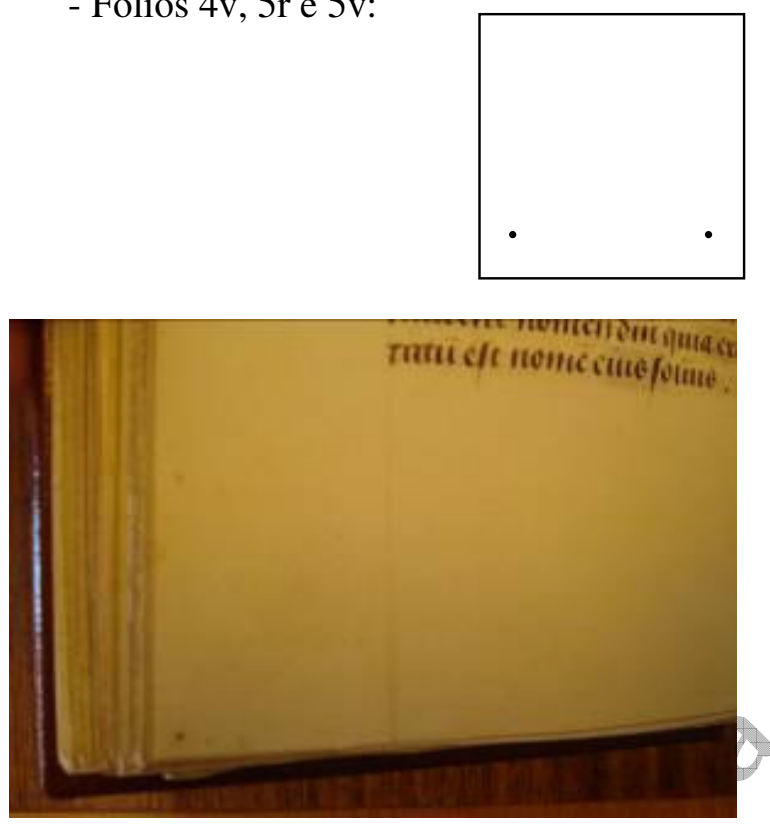

A observação do "Sistema" e "Técnicas" utilizadas são impossíveis de serem observadas (não visíveis).

\subsection{Lineação}

\subsubsection{Processo:}

A lineação foi feita a tinta, com função decorativa, de forma subtil.

\subsubsection{Sistema:}

O Sistema utilizado foi "face-à-face": 


\section{nuntius antiquus}

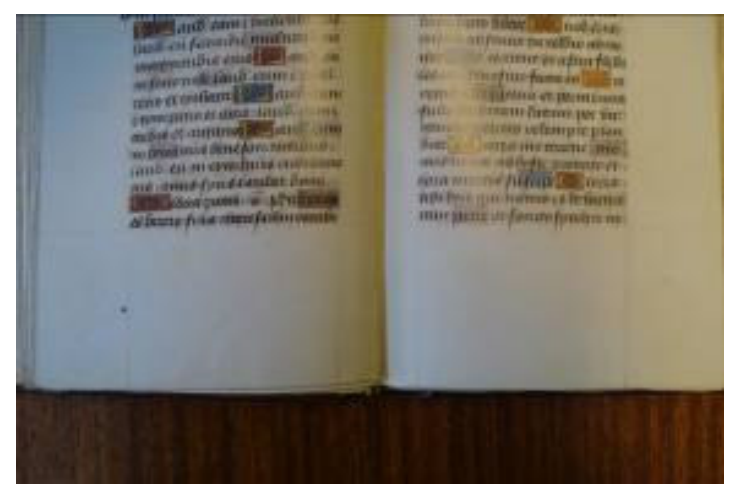

\subsection{Escrita}

\subsubsection{Tipologia:}

As letras bastardas de mão única revelam características da escritura gótica pelo corte e pela clara diferenciação de riscas e linhas amplas, $\mathrm{O}$ texto foi escrito com as letras bem próximas umas das outras e mostram um traço regular. Apenas uma vez antes de começar um novo bloco de texto, no fólio 54, se deixa um parágrafo em branco no centro da página; porém os demais, só aparecem espaços em branco antes de iniciar um novo texto em outra nova página.

\subsubsection{Módulo:}

Analisamos a letra “m” dos seguintes fólios e verificamos a dimensão de 4mm:

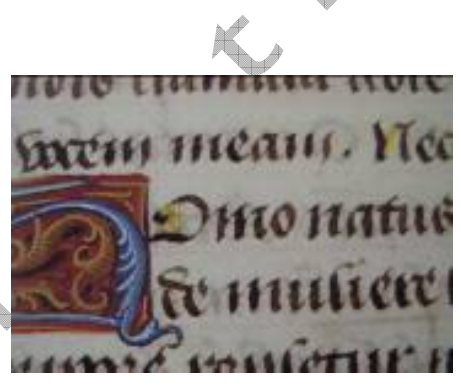

\subsubsection{Mãos:}

Analisamos os fólios 14r, 49r e 99v e podemos através da letra inicial “D” (Deo, Dum e Dmo natus, respectivamente relacionados com os fólios já citados) caracterizar a escritura por apresentarem um traço regular, com a mesma dimensão em todos os fólios: 


\section{nuntius antiquus}

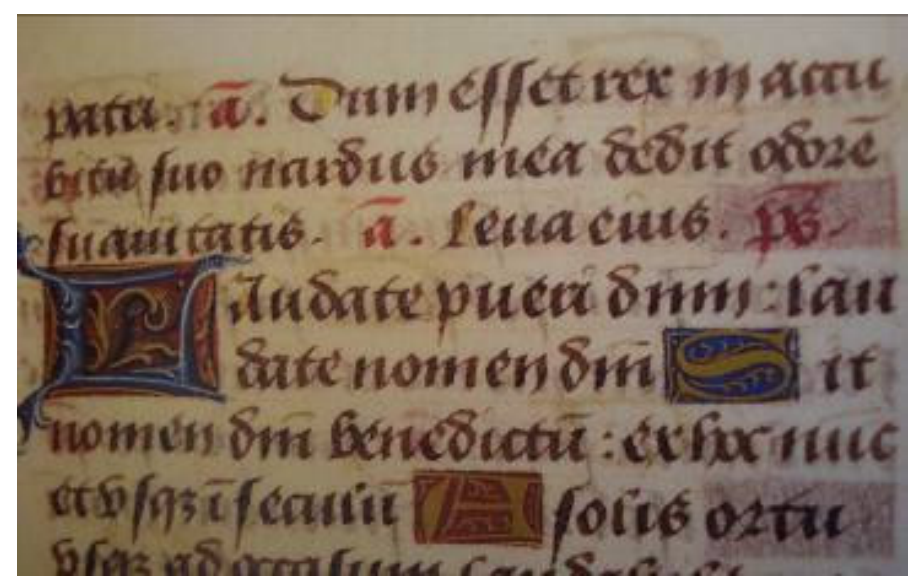

\subsubsection{Copista:}

Não consta nome ou qualquer outra referência sobre o copista.

\subsubsection{Marginália:}

Não possui.

\subsection{Ornamentação}

\subsubsection{Iluminador:}

De acordo com o estudo anterior, realizado por Eberhard Konig, através das excelentes representações da Madonna e do Evangelista Lucas, é atribuída a iluminação a Jean Bourdichon. Segundo Eberhard Konig, o pintor francês exerceu sua atividade em Tours entre os séculos XV e XVI, e é considerado um grande iluminador da Idade Média tardia, sendo identificado como o autor de Les Grandes Heures da rainha francesa Ana de Bretanha, considerada uma de suas grandes e notáveis obras.

\subsection{Ornamentação principal}

\subsubsection{Miniaturas:}

A decoração limita-se ao estritamente necessário e sem grandes peculiaridades. Algumas figuras aparecem cortadas por obedecer à necessidade de adaptar o modelo a um formato de miniatura mais reduzida. Não se observam mal-entendidos graves desde 
o ponto de vista temático. Diante das versões posteriores dos mesmos modelos, as miniaturas vaticanas se distinguem pela especial objetividade e criatividade com que têm sido tratadas.

\subsubsection{Bordaduras e enquadramento:}

As bordaduras em compartimentos são típicas dos finais do século $\mathrm{XV}$, sem que seja possível fazer posteriores precisões. Segundo Eberhard Konig, um pintor italiano do século XVI pintou o centauro do fól. 30v e também retocou a decoração do fólio 23. As ilustrações, além de obter a função em separar as diversas partes de um texto para facilitar a agilidade na leitura, oferecem cenas do mistério savínio, contempladas a cada vez que se liam os textos, convidando também para uma reflexão e meditação sobre as orações:

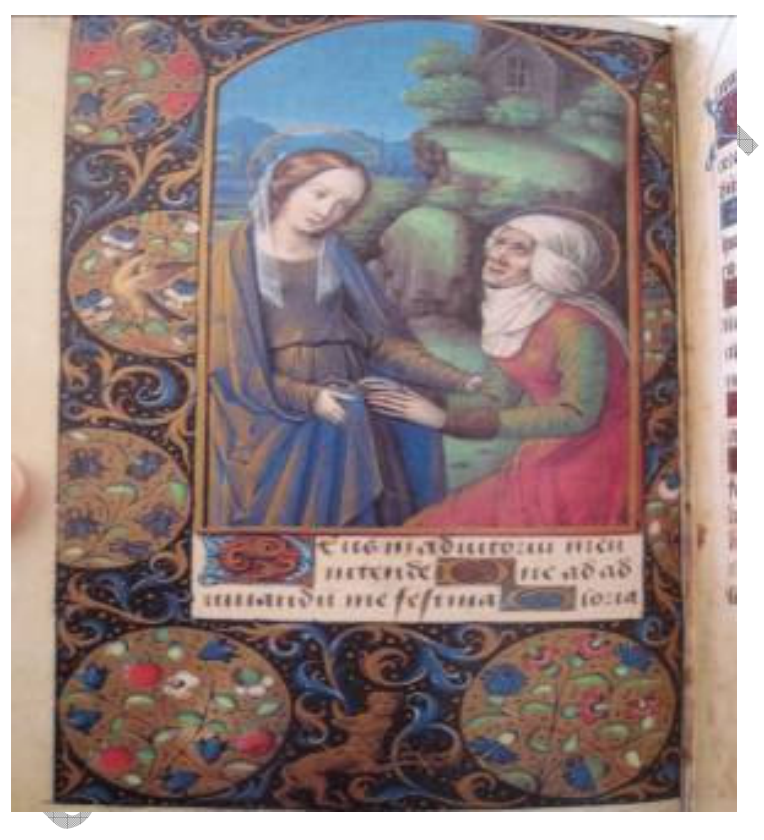

Os fólios 11bis, $12 \mathrm{v}, 14 \mathrm{v}$, e 15r, dos quatro primeiros cadernos contêm as representações dos quatro Evangelistas. Essas imagens não condizem com o conteúdo dos textos, mas foram assim escolhidas, porque na Idade Média era um costume usar os Evangelistas como símbolos:

Fólio 11bis: São João:

Fólio 12v: São Lucas:

Fólio 13bis: São Mateus: 


\section{nuntius antiquus}

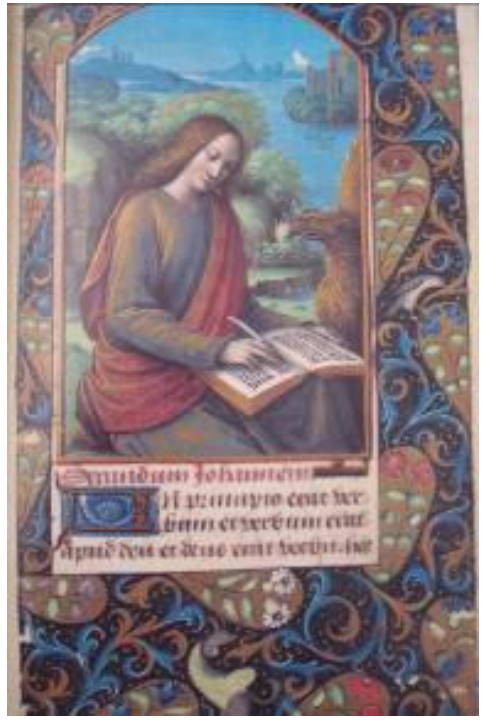

Fólio 14v: São Marcos:
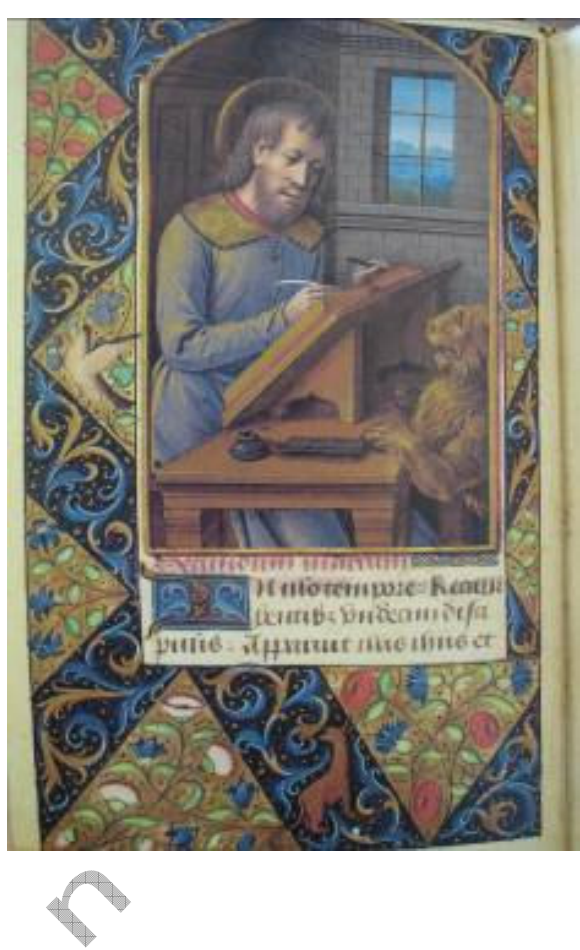
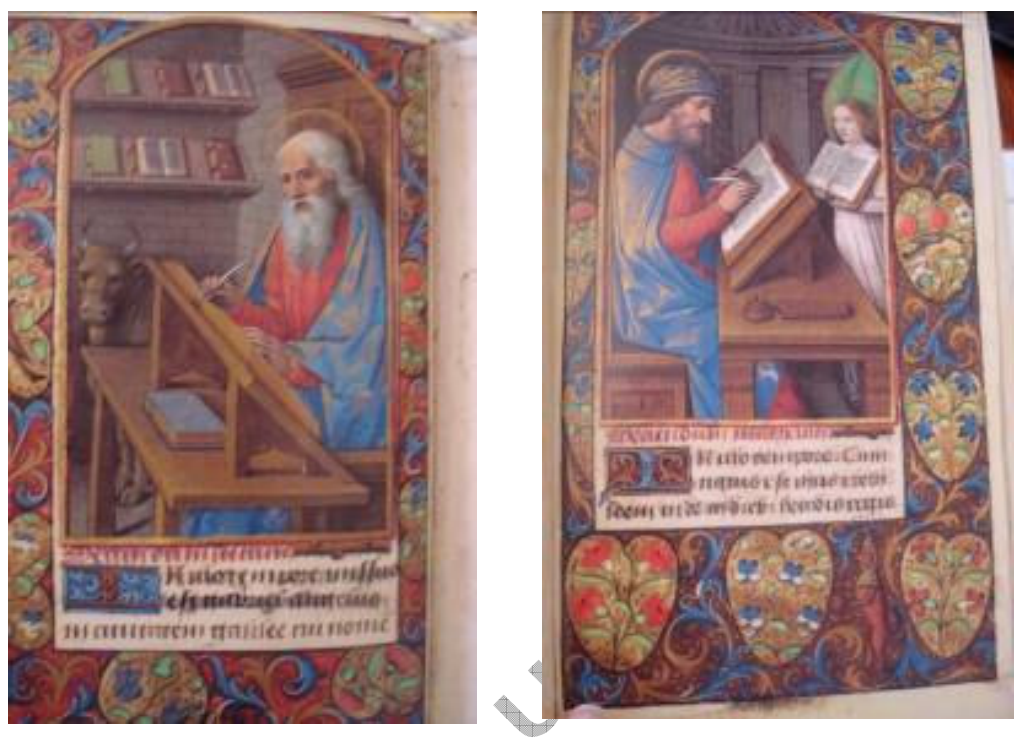

Fólio 15r: Sta. Maria com anjos e S. José:

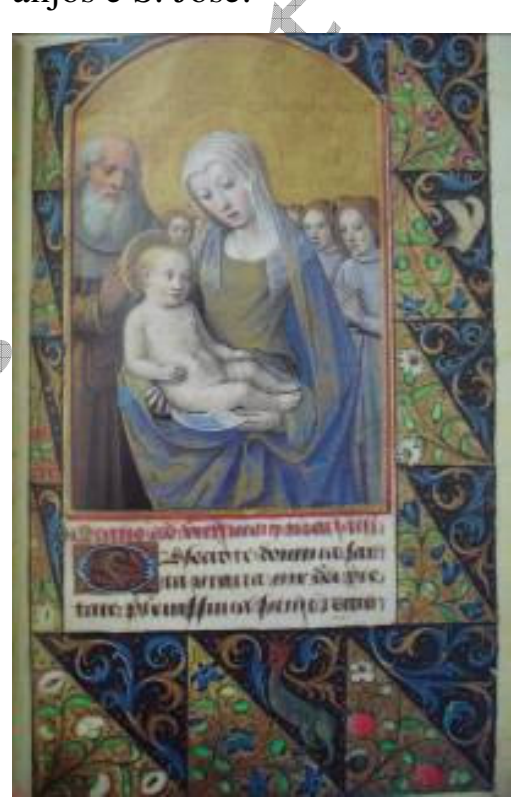

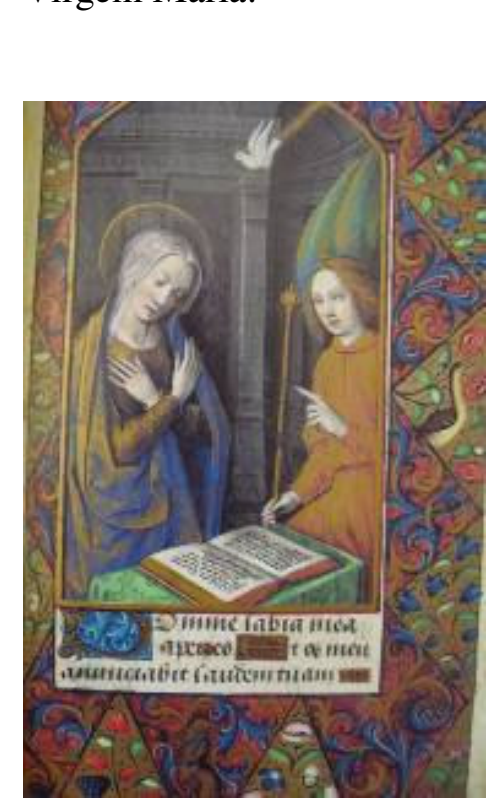

Fólio 23r: Anunciação à Virgem Maria:

Fólio 45v: Apresentação:
Fólio 37v: Adoração:
Fólio 40v: Anúncio: 


\section{nuntius antiquus}
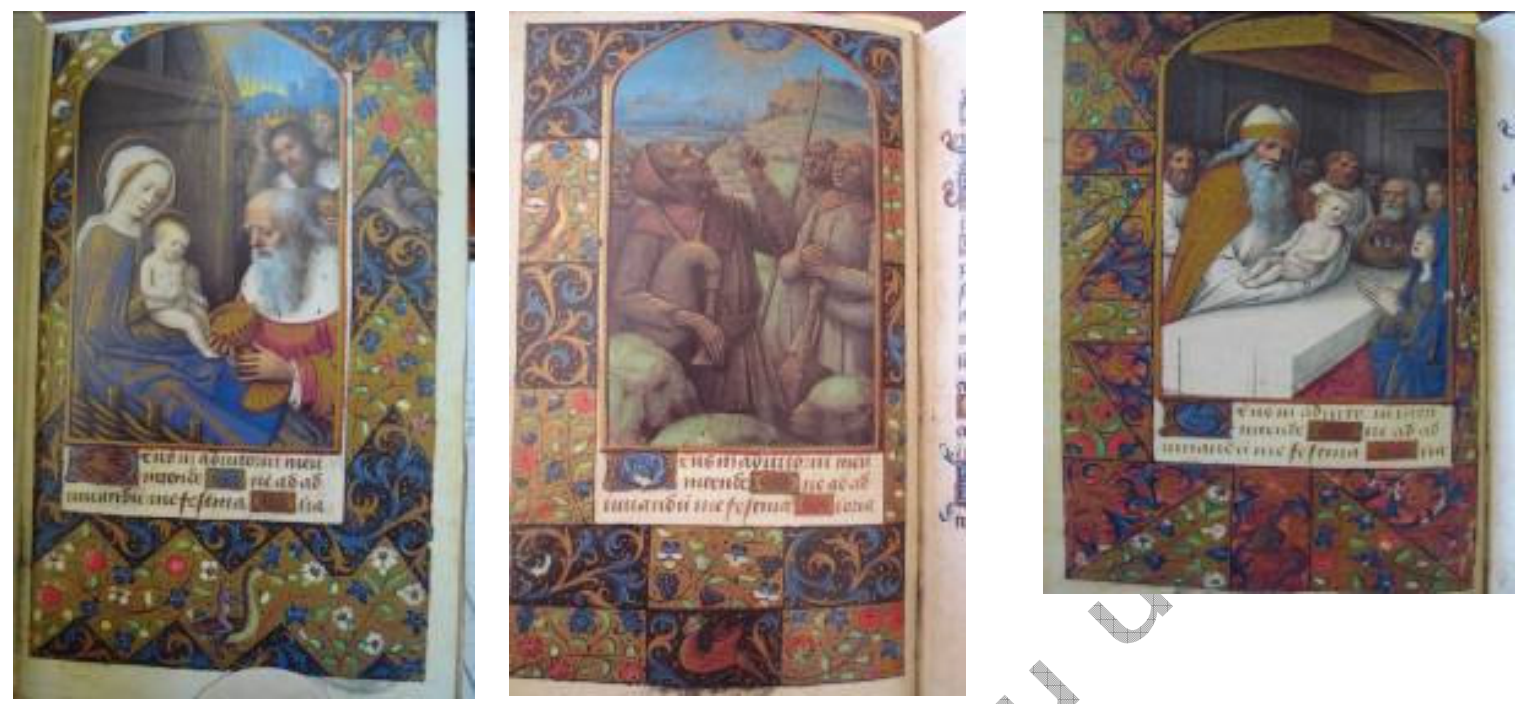

Fólio 48r: Ida ao Egipto:

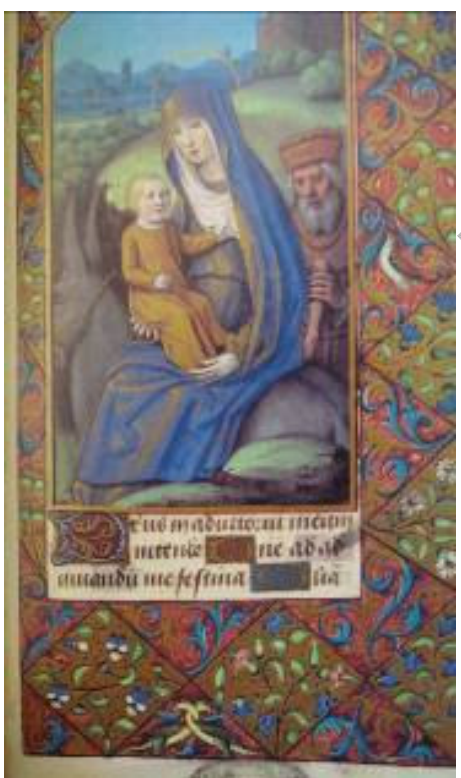

Fólio 52r: Coroação:

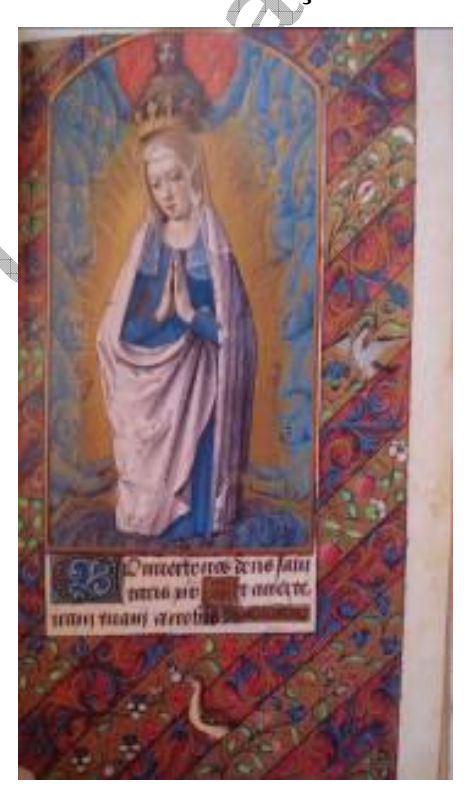

Fólio 67v: Crucificação:

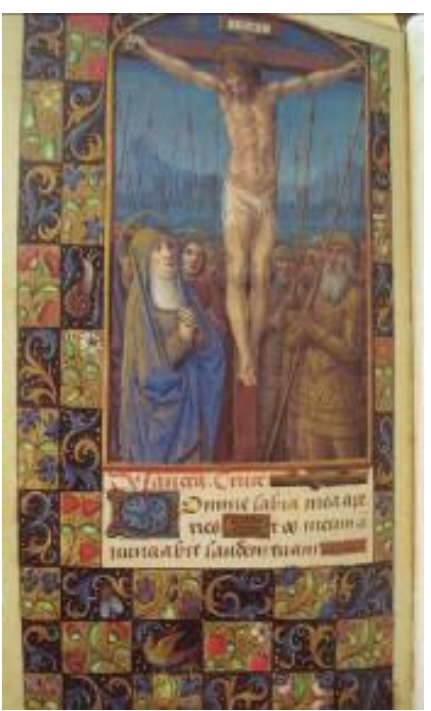

Fólio 70r: Vinda do Espírito Fólio 74r: Penitência do Rei Fólio 88v: Jó na Miséria: 
Santo:

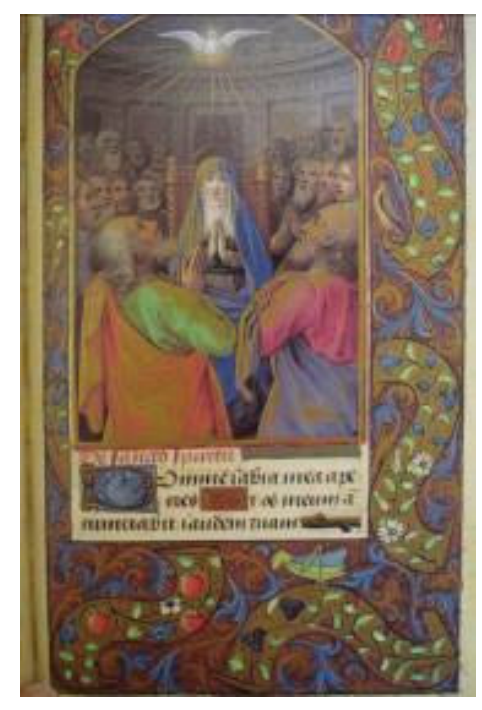

David:

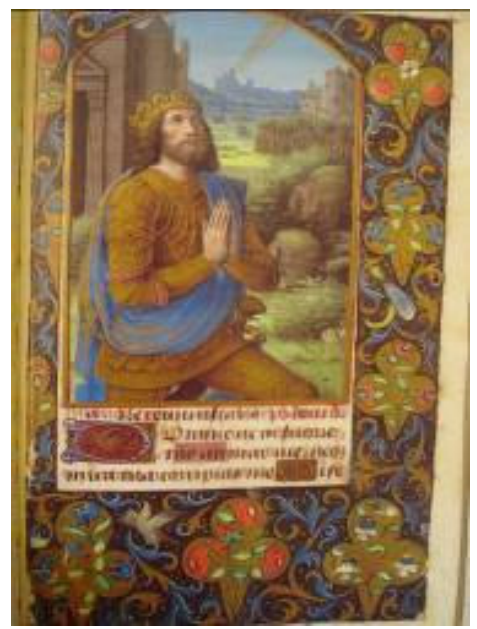

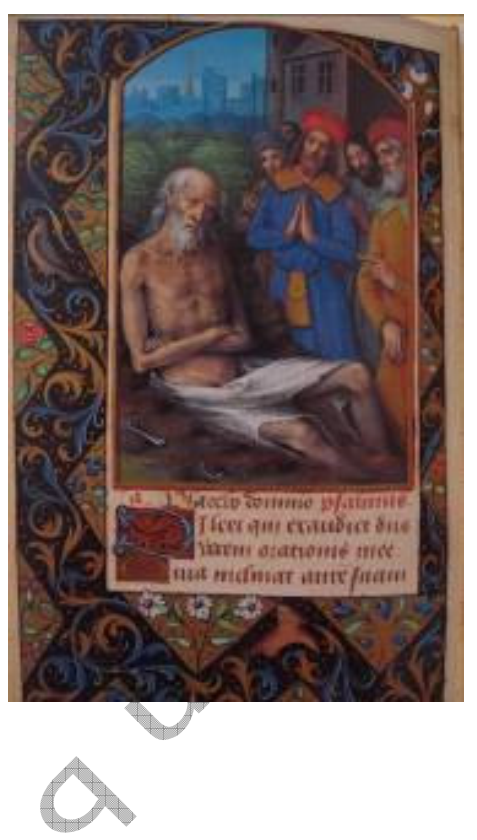

2.8.3 Iniciais historiadas:

O manuscrito não apresenta.

\subsubsection{Iniciais ornadas:}

- Nos textos de orações e versos de salmos existem letras iniciais na primeira linha, coloridas em amarelo dourado alternando com vermelho e azul;

- Nos textos para leitura, Salmos e orações dos santos e do Ofício de Maria existem iniciais no canto na coloração azul sobre o fundo vermelho e vermelho sobre o fundo azul. Existem também algumas iniciais com animais no interior;

- No texto "Oração à Maria” encontramos iniciais também na coloração azul sobre o fundo vermelho e iniciais em vermelho sobre o fundo azul e com animais no interior das iniciais, como podemos verificar a seguir: 

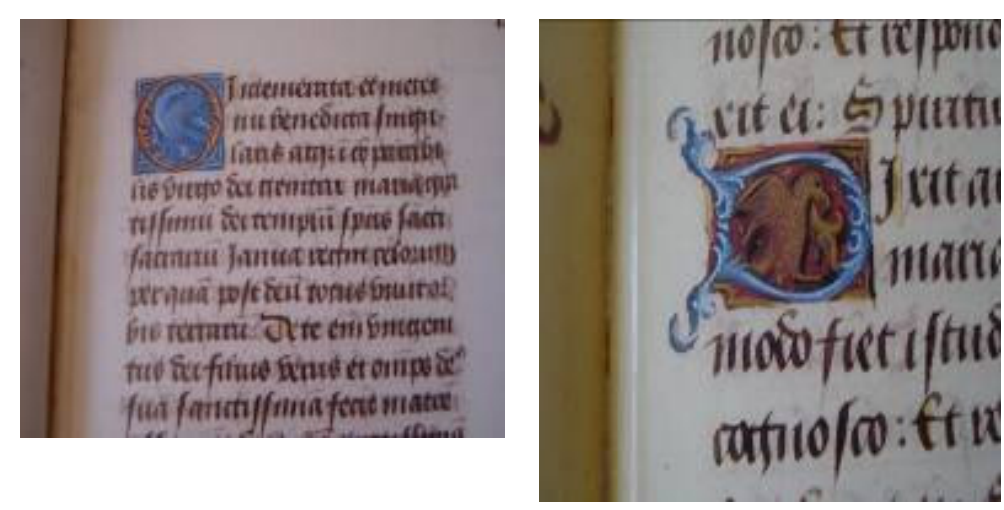

\subsection{Encadernação}

\subsubsection{Natureza:}

O manuscrito foi encadernado entre 1779 e 1798 em pele lisa e resistente de cor marron-carmim.

\subsubsection{Planos:}

$\mathrm{Na}$ frente e verso da encadernação existem a representação de um escudo do Papa Pio VI Braschi, contendo, na parte superior, uma pequena faixa com três estrelas e, logo abaixo, uma planta com grandes flores. Na lateral do Codex, existe a numeração 3781. Essa numeração significica a catalogação realizada no Vaticano.
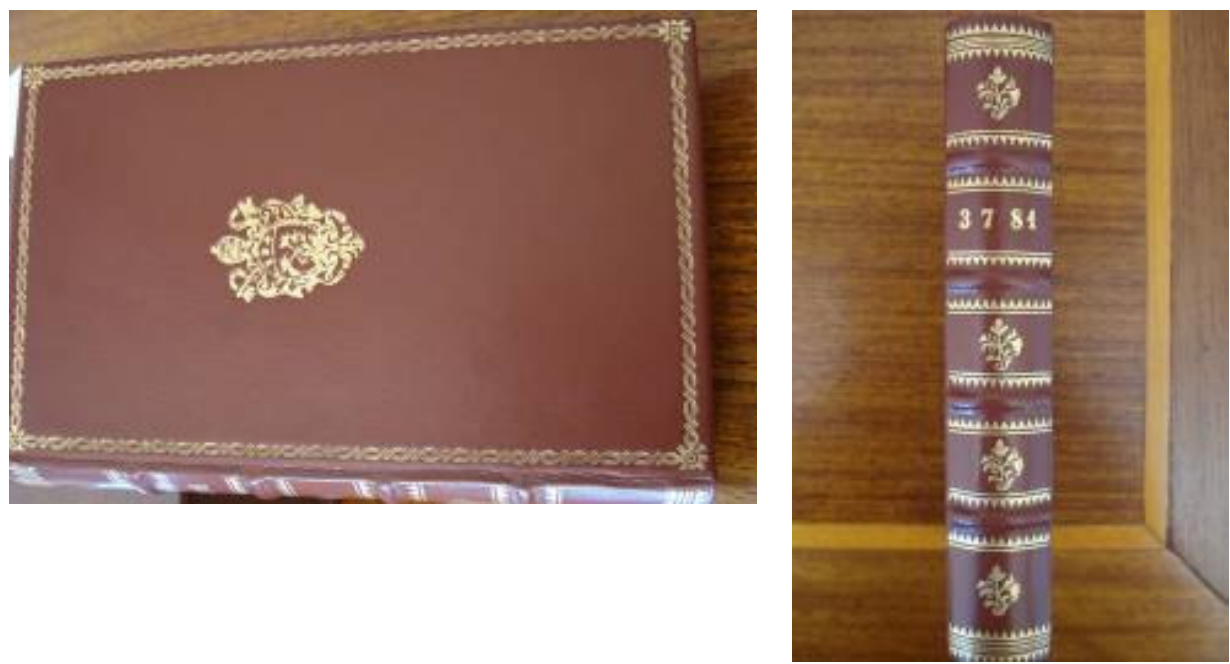


\section{nuntius antiquus}

Faltam as marcas e foram cortados os reclames no fólio 16r. Contém adornos em ouro no formato retangular e também com quatros flores na lateral da encadernação, querendo imitar flores silvestres.

\subsubsection{Nova encadernação:}

Conforme o uso da época, ao realizar uma nova encadernação prescindiu-se por este estar incompleto e em seu lugar foi colocado um simples papel branco. Depois foi colocado um papel menor e sem filigrana, presumidamente também no final do século XVIII. Todas as folhas restantes são de pergaminho, de pele de animal, sem que seja possível hoje determinar de que animal se trata com certeza.

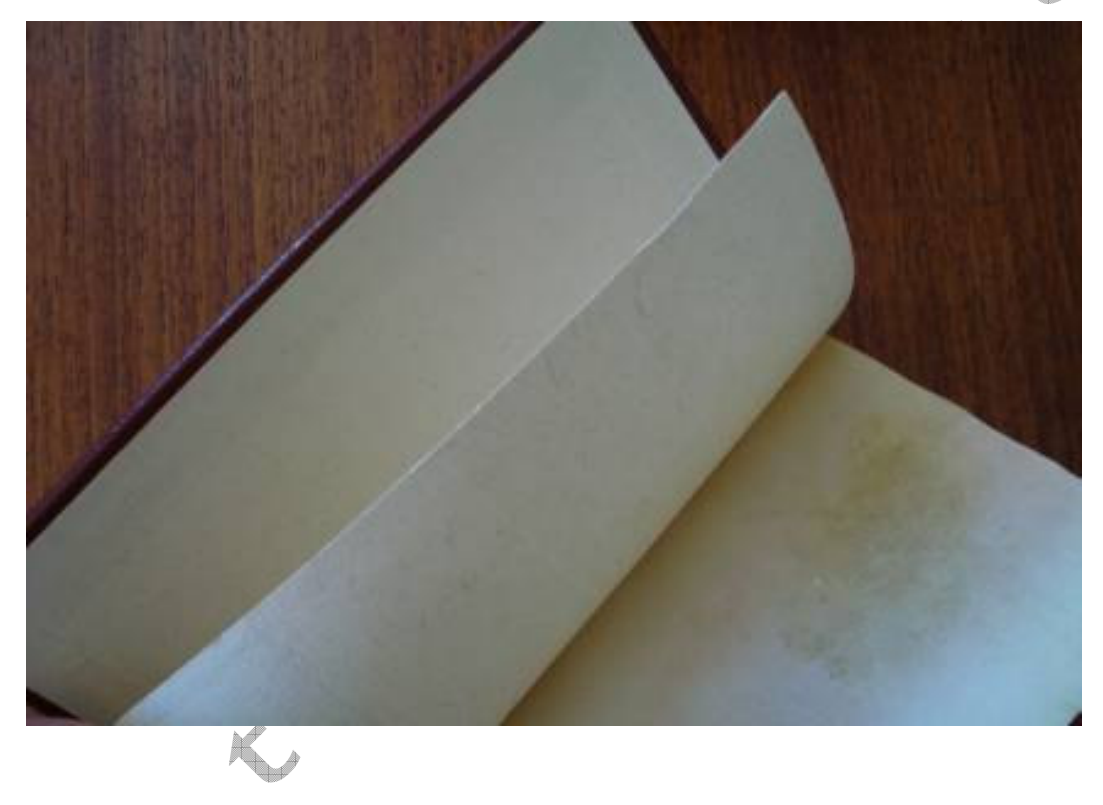

\section{História do ms.}

\subsubsection{Data:}

O Códice “Oficio de La Virgen” não tem título, nome e também não contém informações sobre o autor da obra. Não há conhecimentos de quando se realizou a sua escrita e para quem a estava destinada. Os dados existentes são de observações e comparações realizadas a partir do que se sabe de outros livros da época. Através da observação conheceremos a história do Códice, em que a descrição da obra é que nos levará ao problema relacionado com sua origem e peculiaridade. 


\section{nuntius antiquus}

\subsubsection{Origem e Proveniência:}

Somente a encadernação e o lugar que o manuscrito ocupa nas colecções Vaticanas nos permitem ter algumas conclusões sobre a sua procedência. O Livro de Horas para o uso de Roma, calendário chegou a Biblioteca Vaticana por Paulo V Borghese, pouco depois de 1605. Provavelmente algum colecionador ou bibliográfico gravou seu nome no manuscrito e o novo dono, ao adquiri-lo, arrancou as folhas em que apareciam os dados do antigo colecionador.

\subsubsection{Bordaduras:}

As bordaduras são classificadas como sendo do final do século XV, sem que seja possível fazer uma precisão anterior. Conforme Eberhard Konig, sobre O Ofício da Virgem, um artista italiano do século XVI pintou integralmente o centauro do fol. 30v e retocou também o fol. $23 \mathrm{r}$.

\subsubsection{Relação com outros manuscritos:}

Partindo das representações da Madonna e do Evangelista Lucas, parece que a iluminação deve atribuir-se a Jean Boudichon, pintor que exerceu sua atividade em Tours a cavalo entre os séculos XV e XVI. Assim, apresentam grandes analogias com trabalhos da primeira época de Boudichon, como, por exemplo, o livro de Horas de Carlos VIII da França - Paris, Biblioteca nacional, ms lat. 1370 - e o livro de horas de Carlos de Angulema, também em Paris, ms.lat. 1173.

\subsubsection{Estado de conservação:}

O manuscrito apresenta-se muito bem conservado, com excepção da primeira folha do calendário e também a folha utilizada para substituir o fólio 20r. Existem poucos sinais de utilização e, como já nos referimos, apenas alguns fólios se apresentam retocados. Encontramos também a falta de um pedaço na parte inferior do fólio $43 \mathrm{v}$.

\section{Bibliografia do ms.}

DURRIEU, P. La peinture en France depuis l'avénement de Charles VII jusqu'à la fin des Valois. In: Michel, A. (ed.). Histoire de l'art. Vol. IV, 2, 738-771, p. 95-98. 
EHRENSBERGER, H. Libri Liturgici bibliothecae apostolicae Vaticanae manuscripti. Freiburgi: Br. 1897, p. 353.

LIMOUSIN, R. Jean Bourdichon, peintre et enlumineur. Son atelier et son école. Lyon: 1954, p. 2, 68s. y figs. 102-105.

MICHELINI, L. T. Quinto centenario della Biblioteca Vaticana. Miniature del Rinascimento. Biblioteca Vaticana, Catálogo de la exposición. Città del Vaticano: 1950, n. 272, p. 56 (frontispício).

PLUMMER, J. The last flowering, French painting in manuscripts 1420 - 1530 from American collections. The Pierpont Morgan Library, Catálogo de la exposición. Nueva York: 1982, p. 85.

SALMON, P. Les manuscrits liturgiques latins de la Bibliothèque Vaticane. Vol. 4: Les livres de lectures del l'office du Chapitre. Les livre d'heures (=Studi e Testi, 267). Città del Vaticano: 1971, p. 183.

\section{Conteúdo: textos}

O Livro de Horas não é um livro utilizado para uma leitura recreativa, mas, sim, para a utilização diária dos religiosos e, além disso, o calendário oferecia uma orientação muito útil para qualquer pessoa ao longo do ano.

\subsubsection{Conteúdo do manuscrito:}

1 (ff. $1-11 v$ ) "Calendário". Falta Janeiro. Uma simples enumeração dos dias do mês. Os dias mostravam as festas dos santos e também lembravam o dia da morte dos mesmos, segundo a tradição, nomeados hoje de feriados santos.

2 (ff. 11bis -14v) "Perícopas". Os textos propriamente para a leitura são as quatro passagens dos evangelhos resumidos, que se encontram selecionados de forma resumida a mostrar os acontecimentos mais importantes da vida de Cristo até o momento da sua Ressurreição. Texto escrito para introdução de um sufrágio e termina com uma oração.

3 (ff. 15bis -21v) "As orações marianas". Após o término das leituras dos evangelhos faziam as orações marianas. Orações Obsecro, súplica pela aparição de Maria na hora 
da morte do religioso; Oração Veni et festina pede-se a intercessão de Maria por seu filho pela oração.

4 (ff. 17-22v) “O intemerato”. Oração à Maria pedindo remissão dos pecados.

5 (ff. 23-66) "O Ofício de Maria”. Começa com versículos do Salmos [S.50: 17 e 69:2]; traz a fórmula "Glória ao Pai, ao Filho e ao Espírito Santo..." e salmos [94 e 8:23] que exaltam a Cristo e descrevem as glórias de Maria. Estrutura narrativa que trata de cantar a glória de Deus como criador e de Maria como Virgem. Preces e intercessãó que compõem-se por salmos, leituras bíblicas e não bíblicas.

6 (ff. 67v-69v) "As Horas da Santa Cruz". Orações de textos bíblicos que se repetem toda hora em quatro versos.

7 (ff. 70 - 72) "Horas do Espírito Santo". Assim como no Ofício de Maria, incluem-se versos de Salmos, como introdução das distintas Horas e também com "Recomendação" final, em verso para que a pessoa que recita estas Horas canónicas encomende-se a Cristo, o bem ao Espírito Santo.

\section{8 (ff. 74-81v) "Salmos Penitenciais"}

As recitações dos setes Salmos, chamados penitenciais, recitam-se em muitas ocasiões e motivos diversos, na consagração de igrejas, altares, cemitérios e nas ordenações de clérigos e em extrema-unção, quando, partindo de uma confissão dos pecados, expressada com os salmos bíblicos, o pecador dirige-se a Deus para implorar sua graça e aos santos para pedir sua intercessão.

9 (ff. 88v-109v) "O Ofício dos Mortos". Salmos e versos que se citam e se intercalam com textos mais curtos e leituras com base bíblicas para a confissão dos pecados e a súplica do perdão dos mesmos.

10 (ff. 110 - 113) "Os sufrágios dos Santos"

Os sufrágios dos santos, versos dirigidas à Deus com uma unidade formal, com intenção de reflexão e tributo aos santos. Selecção dos Salmos: [S1.6: 32,38, 51,102,130 e 143]. 


\section{Referências}

ACHTEN, G. Das christtliche Gebetbuch im Mittealter. Berlin/ Wiesbaden: Staatsbibliothek Preussischer Kulturbesitz, 1980 (catálago de la exposición 13).

BOHATTA, H. Bibliographie des Livres d'heures. Horae B.M.V. Officia, Hortuli Animae, Coronae B.M.V. Rosaria und Cursus B.M.V. des XV und XVI. Jahrhunderts. Wien: 1924/ 1999 (segunda edição aumentada).

DELAISSÉ, L. M. J. The importance of books of hours in the history of the medieval book. In: Hoadley, S. (org.). Gatherings in honor of Dorothy Miner. Baltimore: 1974, p. 203-225.

GROTEFEND, H. Zeithechnung des deutschen Mittelaters und der Neuzeit. Hannover/ Aalen, ND: 1891-1898/ 1970. 2 vols.

HARTHAN, J. Stundenbuch des Landesbibliothek. Volumen de comentário al fascímil de Gerhard Stamm. Karlsruhe: 1978.

KONING, E. Standerbuch des markgrafen Cristoph I. von. Baden. Codex Durlach I der Badischen landesbibliothek. Volumen de comentario al facsimile de Gerhard Stamm. Karlsruhe: 1978.

LABARRE, A. Livres d'heures. In: Dictionaire de spiritualité ascétique et mystique. Beauchesne: 1968. Vol. VII, p. 410-431.

LEROQUAIS, V. Les sacramentaires et les missels manuscrits e biliothèques publiques de France. Paris: 1924. Vol. IV.

LIMOUSIN, R. Jean Bourdichon, peintre et enlumineur. Son atelier et son école. Lyon: 1954.

PERDDRIZET, P. Le Calendrier parisien à la fin du moyen age d'après le Bréviarire et les Livres d'Heures (= Publications de la Faculté des lettres de l'Université de Strasbuourg LXIII). Paris: 1937.

\section{Fonte}

Oficio de la Virgen. Introducción de Eperhard Konig (col. Ediciones facsimiles de la Biblioteca Apostolica Vaticana). Madrid: Ediciones Encuentro, 1985.

\section{Outros estudos}




\section{nuntius antiquus}

Ofício da Virgem. Edição fascimilada do Codex Vaticanus latinus 3781 de la Biblioteca Apostólica Vaticana. Zurich: Belser, 1984.

SPINA, S. Introdução à edótica. Crítica textual. São Paulo: EDUSP, 1994.

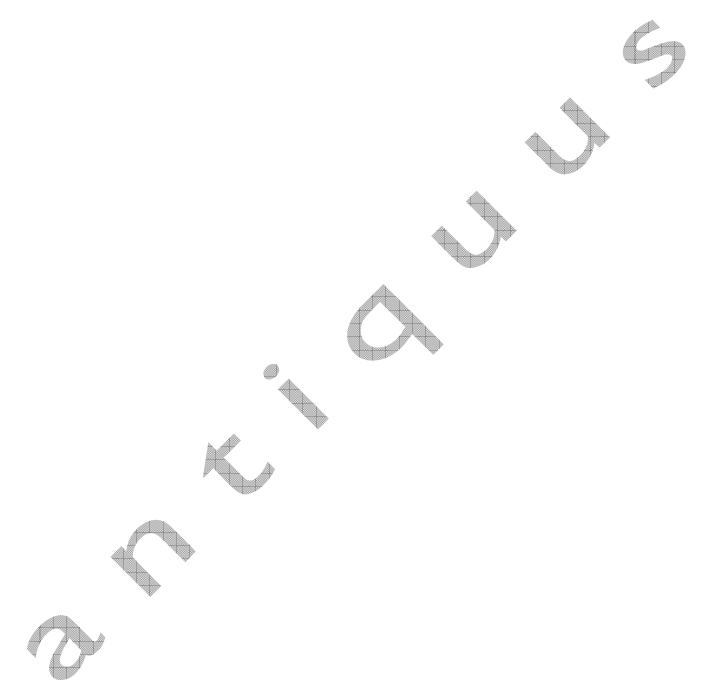

